\title{
A study of the Impact of Nature of Career Planning on Job Satisfaction
}

\author{
By \\ A.M. Anurasiri \\ (GS/MC/2394/2004)
}

\begin{abstract}
A dissertation submitted to the University of Sri Jayewardenepura of Sri Lanka as a partial fulfillment of the requirements for the degree of $M$. Sc. Management (Specialization in Human Resources Management)
\end{abstract}

Faculty of Graduate Studies

University of Sri Jayewardenepura

Gongodawila

Nugegoda

Sri Lanka 


\section{CANDIDATE'S DECLARATION}

"The work described in this thesis was carried out by me under the supervision of

Dr.S.T.W.S. Yapa and a report on this has not been submitted in whole or in part to any university or any other institution for another Degree/Diploma."

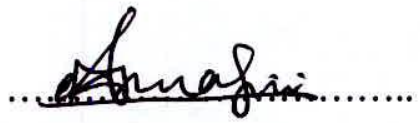

A.M. Anurasiri

(GS/MC/2394/2004) 


\section{CERTIFICATION}

"I certify that the above statement made by the candidate is true and that this thesis is suitable for submission of the University for the purpose of evaluation'?

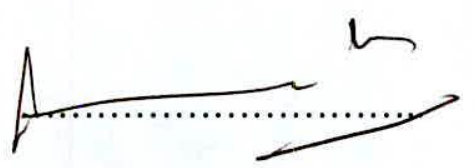

Dr. S.T.W.S. Yapa 


\section{ACKNOWLEDGEMENT}

I wish to express my gratitude to Dr.S.TW.S. Yapa, Senior Lecturer in the Department of Information Technology and Decision Science for the guidance, criticism and suggestions given during the research project. I shall always remember his kindness, patience and the sacrifice of his valuable time even he is in abroad, in discussing \& evaluating my dissertation.

My sincere thanks to Dr. P.D.Nimal, Coordinator of the MSc. (Management) Programme, Faculty of Graduate Studies, University of Sri Jayawardenepura, Sri Lanka, for giving me the opportunity to conduct this research project in the stream of HRM.

My special thanks to Prof. H.H.D.N.P Opatha, my favorite lecturer in Human Resource Management for helping me by teaching Research Methodology as a subject.

I would like to thank my mother and father for the continuous encouragement given to me for my education

I also express my heartiest felt thanks to all respondents who completed the questionnaire \& re-forward them on time, enabling me to do the analysis of the data without delay and contribution made in preparation of my thesis. 
I record my sincere gratitude to my wife for her wonderful support and encouragement and the enormous sacrifice she had to make during my studies.

I express my thanks to my sister for helping me in supporting of finding literature relating to my study.

Thanks also for director (Human Resource Management) and Manager (Personnel and Administration) of Sri Lanka Export Development Board for giving cooperation in the work of my research.

Finally I would like to thank my friends Tissa and Akila for their friendly assistance throughout this period. 


\title{
A Study of the Impact of Nature of Career Planning on Job Satisfaction.
}

\section{A.M. Anurasiri \\ (GS/MC/2394/2004)}

\begin{abstract}
ABSTRCT
This research discusses the nature of career planning of employees and how individuals' career planning of employees affects their job satisfaction. The study is based on primary data gathered from a survey conducted in the Western Province in Sri Lanka. Four hundred employees from both private and public sectors were selected in Western Province. A questionnaire was used to collect both quantitative and qualitative data. The study found that the career planning of employees is not at a satisfactory level. Their career planning has not followed vocational self-concepts at their respective ages. Career planning of employees differ among different occupational categories such as executive and non-executives, and also among different educational and age levels of the workers. Relationship between occupational interest and the current occupation of non-executive employees remains poor, which is also true of the organizational interest and current organization. Therefore, employees are not satisfied with their job. The root cause for non-executive employees' job dissatisfaction is the lack of happiness in the career. It leads to a state of increasing career mobility of employees. As a result, the labor productivity and also the labor specialization of the workers do not develop. Therefore, the career planning should receive adequate attention of employees, employers and government.
\end{abstract}




\section{Table of Content}

Acknowledgement

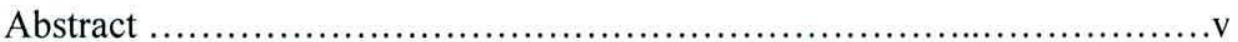

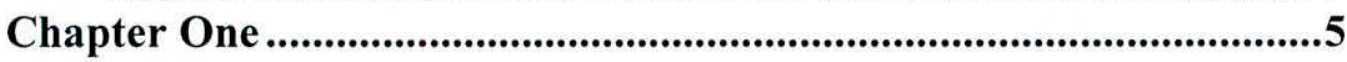

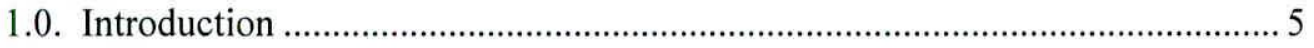

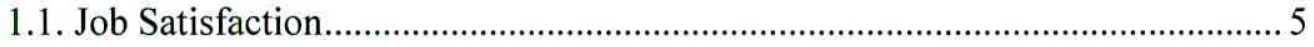

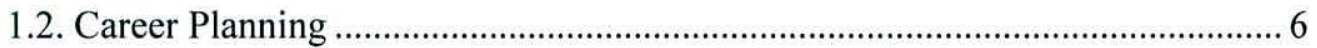

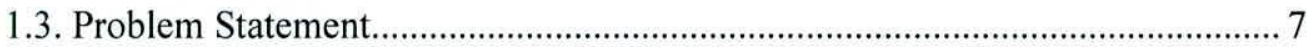

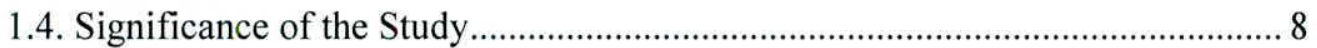

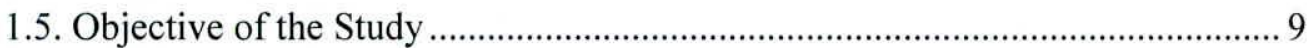

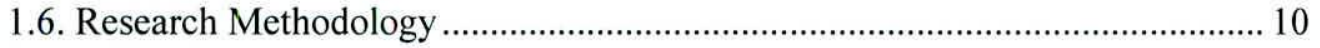

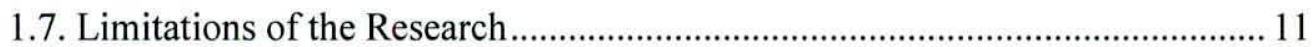

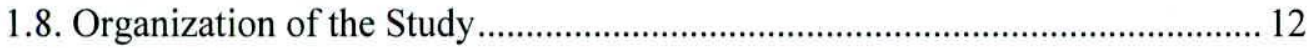

Chapter Two.................................................................................13

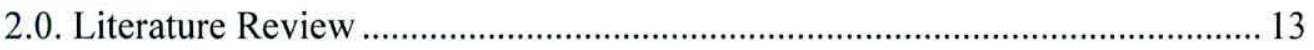

2.1. Career Planning \& Job Satisfaction................................................................. 13

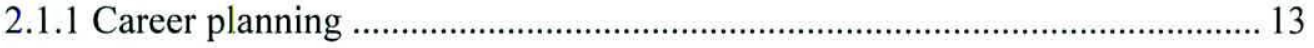

2.1.1.1 The Career Planning Process................................................................... 14

2.1.1.2 The Career Planning Techniques............................................................ 273

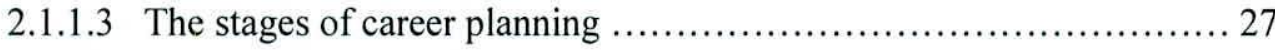

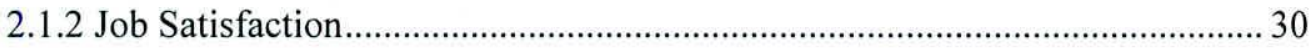

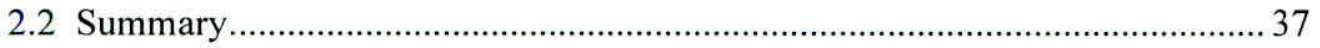

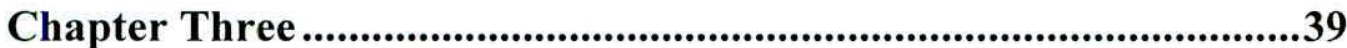

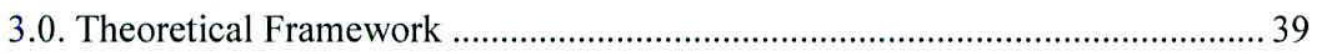

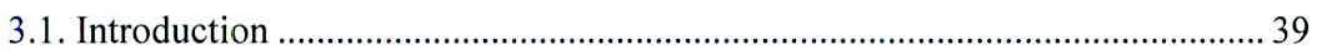

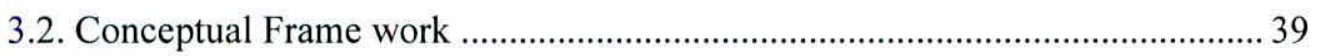

3.3. The Conceptual Model (Schematic diagram of the study) ............................... 40

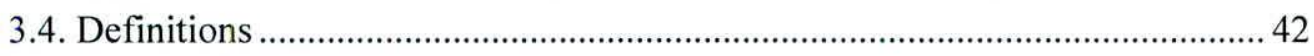

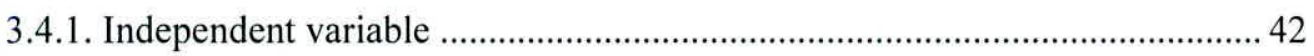

3.4.1.1 The conceptual definition of "Nature of Individuals'career planning" ".... 42

3.4.1.2The Working definition of "Nature of Individuals' career planning"........ 42

3.4.2 Dimensions of "Nature of Individuals' Career Planning".............................. 43 


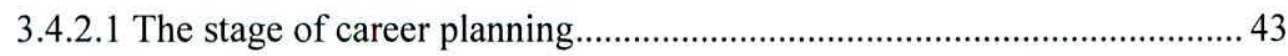

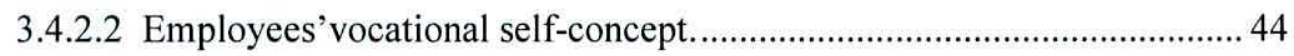

3.4.2.3 Effectiveness of vocational training of employees.................................. 44

3.4.2.4 Employees' awareness of career planning ................................................. 45

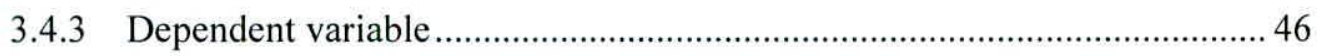

3.4.3.1 The conceptual definition of "Job Satisfaction"....................................... 46

3.4.3.2 The working definition of "Job Satisfaction"............................................ 46

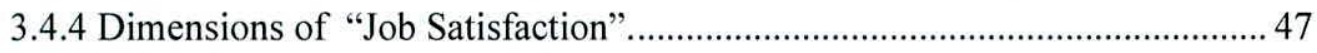

3.4.4.1 Occupational interest and occupational choice. ....................................... 47

3.4.4.2 Organizational interest and organizational choice .................................. 48

3.5 Rationale for Hypotheses and Statement of Hypotheses.................................. 48

3.6 Operatinalization of the Variables.................................................................. 53

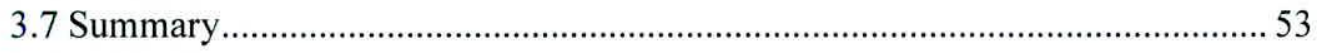

Chapter Four ..............................................................................55

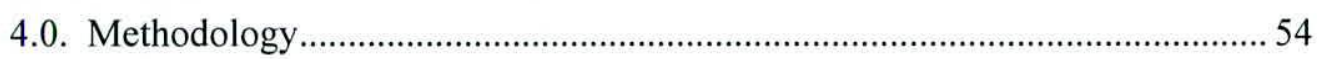

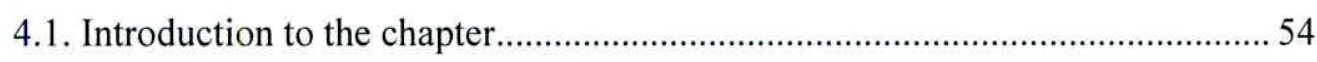

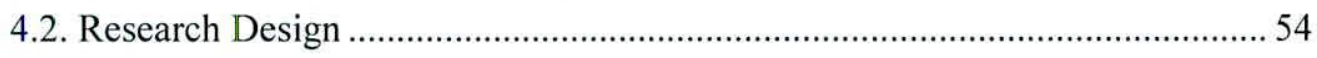

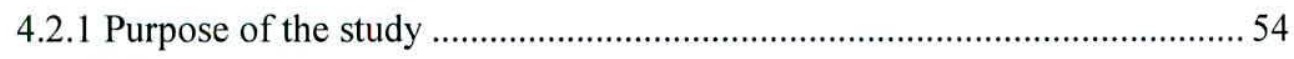

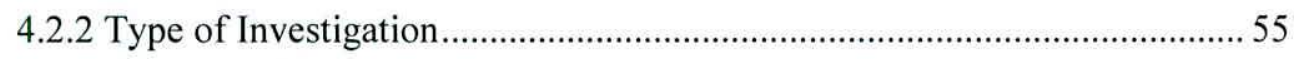

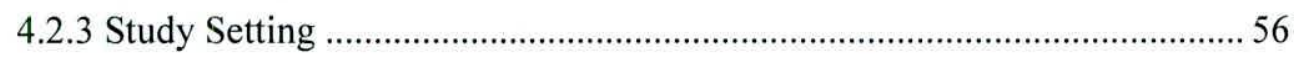

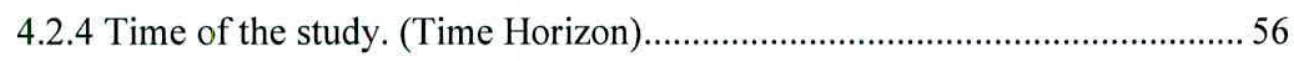

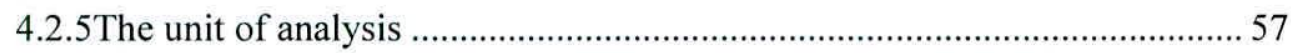

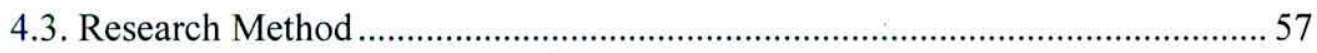

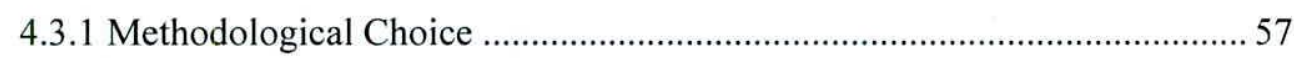

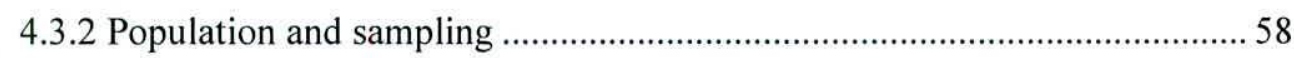

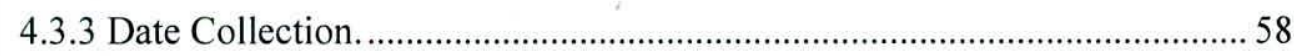

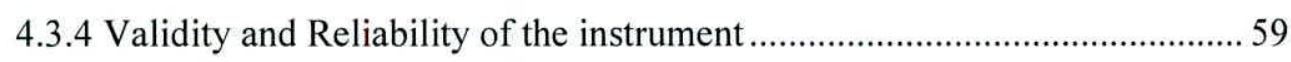

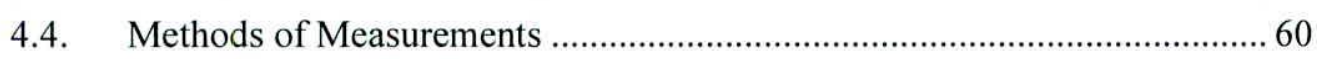

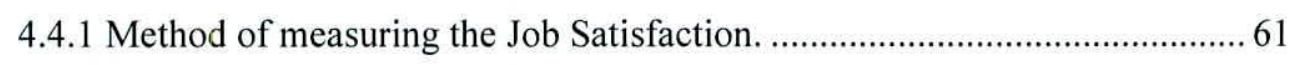

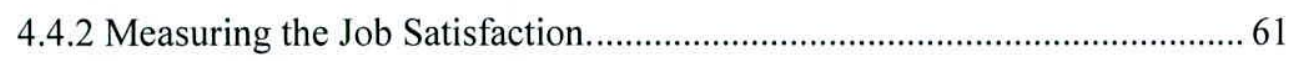

4.4.3 Method of identifying "Nature of Individuals Career planning". ............... 63

4.4.4. Method of measuring the personal characteristics of Individuals ............... 64 


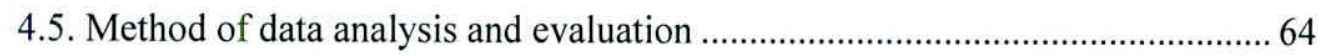

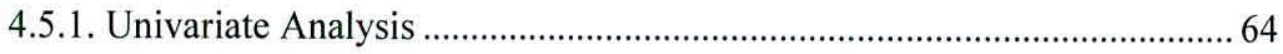

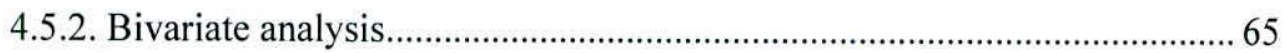

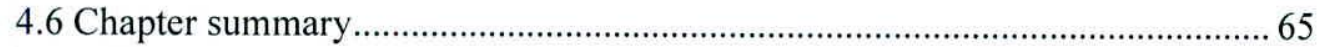

Chapter Five...........................................................................66

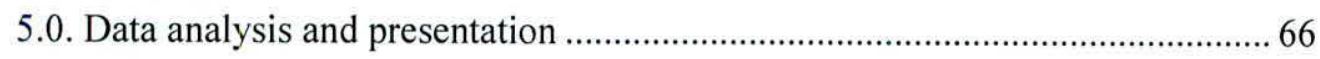

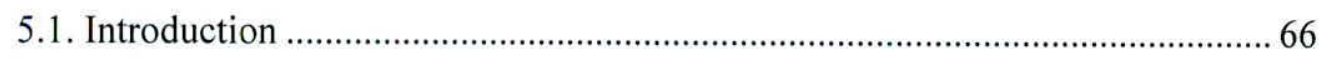

5.2.Analysis of reliability and validity of the instruments ...................................... 66

5.3 Frequency distribution analysis of respondents by their personal

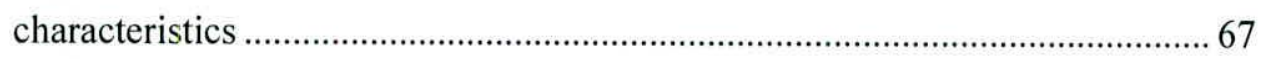

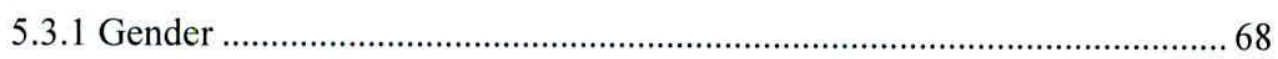

5.3.2 Age 68

5.3.3 Level of Education ..................................................................................... 70

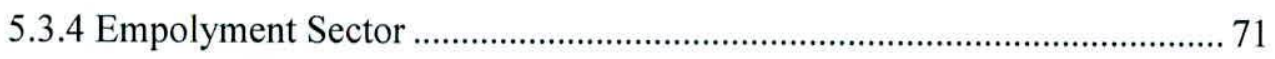

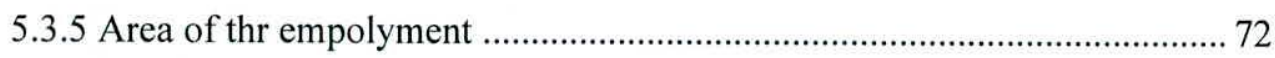

5.3.6 Years of experience of the employees......................................................... 73

5.4 Data analysis relating "stages of career planning" ............................................ 74

5.4.1 Education levels of career plaaning was started......................................... 74

5.4.2 Age ranges of career plaaning was started ................................................ 75

5.4.3 Career planning stages and Job satisfaction .............................................. 76

5.5. Data analysis relating to "vocational self-concept".......................................... 77

5.5.1 The extent of attempt made to achieve vocational self-concept................ 77

5.5.2 The success of achieving Vocational self-concept..................................... 78

5.5.3 Reason for failling Vocational self-concept ............................................ 79

5.5.4 Job satisfaction of employees who achieved vocational self-concept and those who have not achived vocational self-concept. ................................. 80

5.6 Data analysis relating to "Feffectiveness of vocational courses".......................85

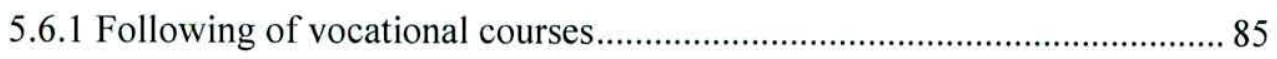

5.6.2 Reason for following vocational courses ................................................... 86

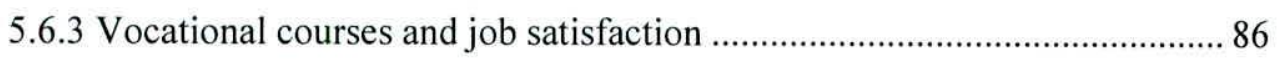

5.7 Data analysis relating to "awareness of career planning" ................................. 88

5.7.1 Degree of awareness of career planning ..................................................... 88 
5.7.2 Career planning awareness and job satisfaction

5.7.3 Employees's plan for next five year.......................................................... 94

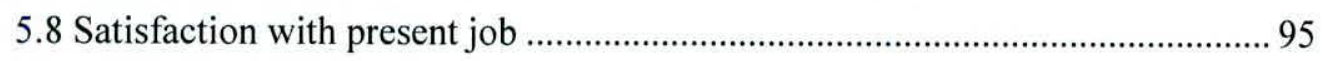

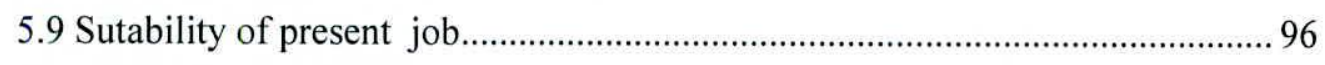

5.10 Preference for current place of work ……........................................................ 97

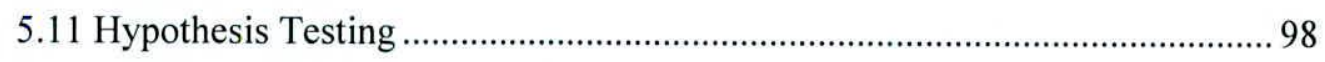

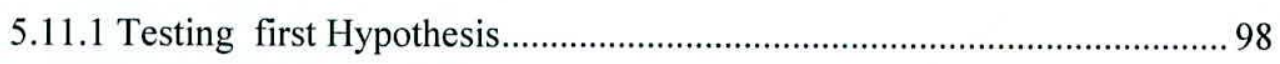

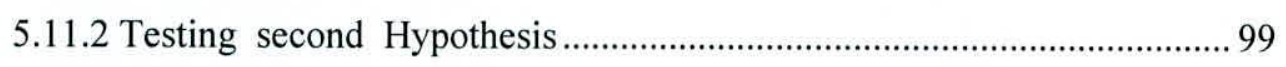

5.11.3 Testing third Hypothesis......................................................................... 100

5.11.4 Testing forth Hypothesis ................................................................... 100

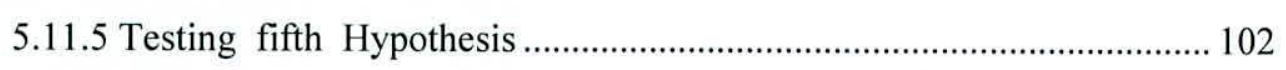

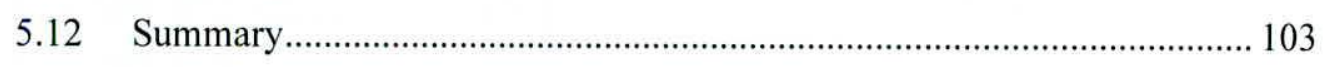

\section{Chapter Six ..............................................................................104}

6.0. Discussion, Conclusion, Recommendation and Implication ........................... 104

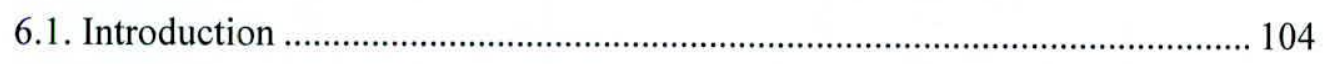

6.2. Discussion of the relationship between Career planning stages and Job satisfaction.

6.3. Discussion of the relationship between Achieving of vocational

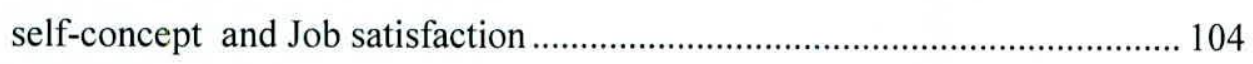

6.4. Discussion on the relationship between Awareness of career planning and Job satisfaction

6.5. Discussion on the relationship between Effectiveness of vocational

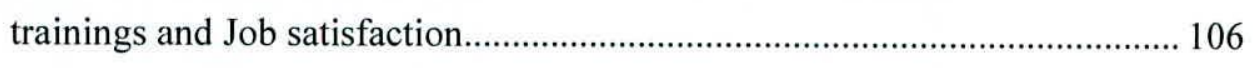

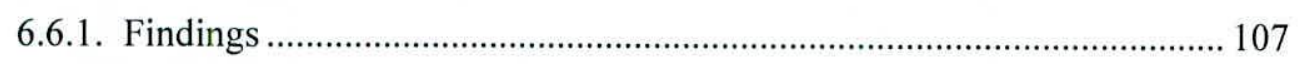

6.6.2. Conclusion and Recommendations ......................................................... 112

6.7 Further Research ................................................... 107

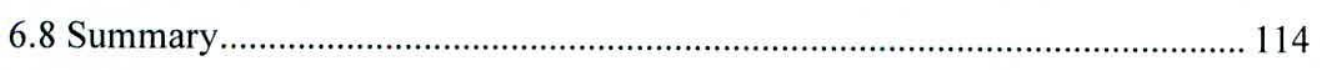

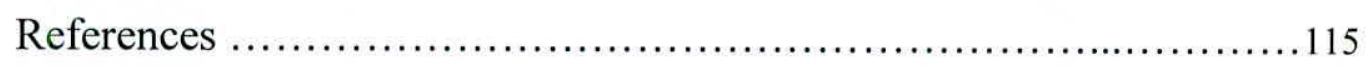

Appendices................................................ 119 


\section{Chapter One}

\section{Introduction-}

\subsection{Job Satisfaction}

Job satisfaction is a very important attribute which is frequently measured by organisations and it can be an important indicator of how employees feel about their jobs and a predictor of work behaviours such as organizational citizenship, absenteeism, and turnover.

Job satisfaction has been defined as a pleasurable emotional state resulting from the appraisal of one's job; an affective reaction to one's job; and an attitude towards one's job. Weiss (2002) has argued that job satisfaction is an attitude but points out that researchers should clearly distinguish the objects of cognitive evaluation which are affect (emotion), beliefs and behaviours. This definition suggests that we form attitudes towards our jobs by taking into account our feelings, our beliefs, and our behaviors. Gilmer and Deci (1977) concluded that "workers' attitudes toward their jobs reflect the extent to which they are satisfied with their jobs and their work lives".

Job satisfaction has a rather tenuous correlation to productivity on the job. This is an important fact to researchers and businesses, as the idea that satisfaction and job performance are directly related to one another is often cited in the media and in some non-academic management literature. (More details about job satisfaction will be discussed in chapter 2, Literature Review). 


\subsection{Career Planning}

A career can be defined as a person's progress within an occupation or series of occupations. However, a career is more than just a job, or working, or one's occupation. It also includes your progress through life, your growth and development in vocational and vocational areas of life (www.fredonia.edu/edo).

Career planning is the deliberate process through which someone becomes aware of personal skills, interests, knowledge, motivation, and other characteristics; acquires information about opportunities and choices; identifies career related goals ; and establishes action plans to attain specific goals (Gary Desler, 2005).

Most of people think that there is only one occupation that is best suited for them , but there are really several that may be good choices. The secret is to identify those occupations in which one has a high probability for success and happiness. Whether their career goals are accounting, theatre arts, or environmental sciences, there are general skills, which will be required regardless of the career they pursue. These skills include the ability to read, write, compute, think critically, and communicate in an effective manner. For the most part, these skills are developed and/or sharpened in general education courses. These skills, along with effective career planning techniques, and the ability to cope with ambiguity in a changing environment, will enable you to overcome obstacles throughout work life. (More details about career planning will be discussed in the chapter 2, Literature Review). 


\subsection{Problem Statement}

Individuals can gain career happiness by planning their careers and following those plans during their career span. Workers can enjoy career happiness by finding or developing careers that allow them to express their core identities and values that tap in to their true essence. People who perform jobs which are aligned with their career plans experience a greater sense of self-esteem from doing what one is able to do and wants to do. Once an individual directs his/her career via his/her career plan, there is greater possibility of being a pioneer/expert in his/her area of specialization, since a job selected, based on one's career planning stands for personal values of the jobholder. Thereby leaving no room for conflict between the job and the jobholder. It is a general fact that the productivity of private sector organizations depends on their managerial efficiency. Managerial efficiency highly depends on the extent to which workers are satisfied with their jobs and to which extent they are motivated towards their job performance. When a person is doing what he/she really wants, there will be a deeper sense of personal satisfaction than ever before (Clark, 1999: 93). That means: if individuals can have the job what he planned, he may have the better satisfaction of the job.

However, no substantive empirical study has been conducted to describe the impact of "nature of individual career planning" on "job satisfaction" in SriLanka. Therefore it is important to find the Impact of Nature of Career Planning on Job Satisfaction. This is the research gap that is being primarily addressed in this research. 


\subsection{Significance of the Study}

Job satisfaction describes how content an individual is with his or her job. It is a relatively recent term since in previous centuries the jobs available to a particular person were often predetermined by the occupation of that person's parent. There are a variety of factors that can influence a person's level of job satisfaction; some of these factors include the level of pay and benefits, the perceived fairness of the promotion system within a company, the quality of the working conditions, leadership and social relationships, and the job itself (the variety of tasks involved, the interest and challenge the job generates, and the clarity of the job description/requirements). But, although some organizations try to enhance the job satisfaction of the employees by addressing the above mentioned factors, they have been unable to satisfy employees for the level they expected. That means that there may be any other factors that influence to the job satisfaction.

If somebody does what he wanted to do, he will be ended up with successful results. It is true for employees too. Individuals can gain career happiness by planning their careers and following those plans during their career span. Workers can enjoy career happiness by finding or developing careers that allow them to express their core identities and values that tap in to their true essence. People who perform jobs which are aligned with their career plans experience a greater sense of self-esteem from doing what one is able to do and wants to do. Once an individual directs his/her career via his/her career plan, there is greater possibility of being a pioneer/expert in his/her area of specialization, since a job selected, based on one's career planning stands for personal values of the jobholder. Thereby leaving no room for conflict between the job 
and the jobholder. Then it prevents role erosion, job stress and role conflict. On the other hand, it increases role expectation and strengthens the feeling of self-efficacy. As workers enjoy the joy of working than struggling with their jobs, there is less possibility to catch them with stress related illness and other occupational diseases. The match between job and the jobholder creates the foundation for connecting the workers' spirit, with the work serving as a tool of employee motivation.

Therefore, it is essential need to study "Nature of Individual Career planning and its influence to the Job Satisfaction?"

Moreover, it is hoped that this study will help in identifying the impact of "Nature of individuals' career planning" on "Job satisfaction. There are enough theoretical explanations with regard to career planning and job satisfaction. But no empirical study has been done in Sri Lanka related to investigate the impact of career planning on job satisfaction. Hence there is a gap in the knowledge the findings of this study would become original contribution to the knowledge. Future researchers also can use the findings of this study for conduct their research work.

\subsection{Objective of the Study}

The general objective of this study is to find the impact of nature of individuals' career planning on job satisfaction". This study attempts to achieve the following specific objectives.

1. To identify the career planning stages which give higher job satisfaction, for starting the career planning. 